\title{
MASTIC-G-POLY (ACRYLAMIDE): MICROWAVE-ASSISTED SYNTHESIS AND CHARACTERISATION
}

\author{
MOHIT KUMAR*, SURAJPAL \\ School of Pharmaceutical Sciences, Lovely Professional University Phagwara, Jalandhar, Punjab, India \\ Email: mohitmehta9@gmail.com
}

Received: 18 Dec 2020, Revised and Accepted: 04 Feb 2021

\section{ABSTRACT}

Objective: The objective of the present investigation was the synthesis of grafted co-polymer gum mastic using acrylamide as the monomer.

Methods: 3-factor 3-level response surface Box-Behnken design, which requires 15 runs including three replicates of the central run, was used for the synthesis of graft copolymers of mastic gum with acrylamide using ceric ammonium nitrate as the free radical initiator. The critical synthesis and process parameters; CSPP (A = concentration of monomer, $\mathrm{B}=$ concentration of initiator and $\mathrm{C}=\mathrm{Temperature})$ to generate design space and optimize formulation with an aim to obtain critical quality attributes (CQA, Y1 =\% Yield, Y2 =\% Grafting, Y3 =\% grafting efficiency).

Result: Formulation F14 having a maximum \% yield of $75.89 \%$ with $\%$ grafting of $210 \%$ and $\%$ grafting efficiency $51.57 \%$ was selected as best.

Conclusion: The microwave-assisted grafted mastic gum was prepared successfully and optimized by using Box Behnken design

Keywords: Mastic Gum, Microwave-assisted grafting, Acrylamide, Box Behnken design

(C) 2021 The Authors. Published by Innovare Academic Sciences Pvt Ltd. This is an open access article under the CC BY license (https://creativecommons.org/licenses/by/4.0/) DOI: https://dx.doi.org/10.22159/ijap.2021v13i2.40551. Journal homepage: https://innovareacademics.in/journals/index.php/ijap

\section{INTRODUCTION}

Polymeric materials are widely used in pharmaceutical formulations, especially for making modified release formulations. Their specialty of controlling drug release rate is because of their structure and composition. These are long-chain compounds formed by monomers. These chains can be linear, branched and cross-linked $[1,2]$

Grafted co-polymer includes a previously formed polymer backbone onto which the other species of polymer chains, which are of varying chemical nature, are attached at different sites of the polymeric backbone. The connected side chains may be comprising of a monomeric unit or of a binate mix. The one which is having one monomer only is easier to synthesize and generally happens in a solitary step; nevertheless grafting in the case of binate blend requires to be done in continuous and stepwise addition of the monomers [3-5].

A grafted co-polymer shows macromolecular series with single or multiple types of block molecule series associated with core polymeric backbone chain as various side chains. Graft polymerization is one of the most convenient methods to use various natural polysaccharides in extended drug delivery systems [6,7]. Nowadays in polymer science the synthesis and use of these grafted copolymers in various applications is a major area for researchers. Employment of a peculiar or selected functional groups into the polymer affects the various chemical, physical as well as rheological properties of the compound In comparison with other Asian countries, India is a rich source for these because of the inherent biodiversity [8-10]

The aim of the study was the development of a modified polymer from a natural gum by using a monomer and initiator.

\section{MATERIALS AND METHODS}

\section{Materials}

Mastic gum was obtained from Mastic grower association (Greece) acrylamide was purchased from Fisher Scientific Pvt. Ltd. (India), ceric ammonium nitrate was purchased from Qualikem Laboratories (India). Ethanol, petroleum ether and methanol were purchased from Merck, Mumbai, India.

\section{Method}

\section{Grafting copolymerization of mastic gum}

Mastic-g-poly(acrylamide) was prepared by redox initiator method An accurately weighed $1.4 \mathrm{gm}-2.8 \mathrm{gm}$ of acrylamide was solubilized in $30 \mathrm{ml}$ of ethanol in a beaker and in another beaker, $0.5 \mathrm{gm}$ of fine powder of mastic gum was dissolved in $10 \mathrm{ml}$ of ethanol. Both these above solutions were mixed and an initiator i.e. ceric ammonium nitrate (CAN) of different concentrations (25 mg-75 mg) was added. This uniform solution was allowed for stirring at $60^{\circ} \mathrm{C}$ for $4 \mathrm{~h}$ followed by solvent evaporation under reduced pressure. The residue was washed with methanol: water (70:30) to remove any homopolymers. The precipitated gum was dried under vacuum at $40{ }^{\circ} \mathrm{C}$ to obtain the dried product $[11,12]$

\section{Experimental design}

A 3-factor 3-level response surface Box-Behnken design, which requires 15 runs, including three replicates of the central run, was used for the synthesis of graft copolymers of mastic gum with acrylamide using ceric ammonium nitrate as the free radical initiator. The critical synthesis and process parameters; CSPP (A = concentration of monomer, $\mathrm{B}=$ concentration of initiator and $\mathrm{C}=$ Temperature) to generate design space and optimize formulation with an aim to obtain critical quality attributes (CQA, Y1 $=\%$ Yield, Y2 $=\%$ Grafting, Y3 =\% grafting efficiency). Different concentration of three CSPP (as shown in table 1) viz., $\mathrm{A}=$ polyacrylamide with their low (1.4 g), medium (2.1 g) and high level (2.8 g) and B = ceric ammonium nitrate with their low $(25 \mathrm{mg})$, medium $(50 \mathrm{mg})$ and high level $\left(75 \mathrm{mg}\right.$ ) and Temperature low $\left(40{ }^{\circ} \mathrm{C}\right)$, medium $(50$ $\left.{ }^{\circ} \mathrm{C}\right)$ and high level $\left(60^{\circ} \mathrm{C}\right)$ were selected. Box behnken design was applied using design expert software [13, 14] (version 7.0, Statease. Inc, USA) and the polynomial equation generated was given below:

$$
Y=\beta_{0}+\beta_{1} \cdot A+\beta_{2} \cdot B+\beta_{3} \cdot C+\beta_{4} \cdot A \cdot B+\beta_{5} \cdot A \cdot C+\beta_{6} \cdot B \cdot C+\beta_{7} \cdot A_{1}^{2}+\beta_{8} \cdot B_{2}^{2}+\beta_{9} \cdot C_{2}^{2}
$$

Where $\mathrm{Y}$ is the dependent variable, $\beta_{0}$ is the arithmetic mean response of the 15 runs and $\beta_{i}\left(\beta_{1}, \beta_{2}, \beta_{3}, \beta_{4} . \beta_{9}\right)$ is the estimated coefficient for the corresponding factor $\mathrm{A}, \mathrm{B}$ and $\mathrm{C}$, which represents the average results of changing one factor at a time from its low to high value. The interaction term (A. B, A. C and B. C) depicts the changes in the response when three factors are simultaneously changed. The polynomial terms $\mathrm{A}^{2}, \mathrm{~B}^{2}$ and $\mathrm{C}^{2}$ are included to investigate the quadratic model. The magnitude of coefficients in the polynomial equation has either a positive sign indicating a synergistic effect or a negative sign indicating an antagonistic effect. Best fitting experimental model (linear, two factor interaction and quadratic) was taken statistically on the basis of comparison of 
several statistical parameters like coefficient of variation (CV), multiple correlation coefficient $\left(\mathrm{R}^{2}\right)$, adjusted multiple correlation coefficient (adjusted $\mathrm{R}^{2}$ ), predicted residual sum of square and graphically by Contour Plot, 3D response surface plot provided by Design Expert software. The level of significance was considered at a p-value $<0.05$. The box Behnken design matrix is shown in table 2 .

Table 1: Levels of independent variables in box behnken design

\begin{tabular}{|c|c|c|c|c|c|}
\hline Factor & Name & Units & Low level & Mid-level & High level \\
\hline $\mathrm{A}$ & Acrylamide amount & gm & 1.4 & 2.1 & 2.8 \\
\hline B & CAN amount & $\mathrm{mg}$ & 25 & 50 & 75 \\
\hline $\mathrm{C}$ & Temperature & ${ }^{\circ} \mathrm{C}$ & 40 & 50 & 60 \\
\hline
\end{tabular}

\section{FT-IR spectroscopy}

The grafting on the polymer backbone was confirmed by FT-IR (Nicolet) and infrared spectra of native and grafted mastic gum and acrylamide were recorded in a range from 4000 to $500 \mathrm{~cm}^{-1}$ [15].

\section{Differential scanning calorimetry}

Differential scanning calorimetry (DSC) was used for screening. The specified samples were hermetically sealed in a flat-bottomed aluminum pan and heated in the differential scanning calorimeter (DSC Mettler Toledo, Mumbai, India) in an atmosphere of nitrogen and the rate of flow was $25 \mathrm{ml} / \mathrm{min}$. A temperature range of $25^{\circ} \mathrm{C}$ to $220^{\circ} \mathrm{C}$ was used, and the heating rate was $10^{\circ} \mathrm{C} / \min [16,17]$

\section{$\mathrm{X}$-ray diffractometry}

$\mathrm{X}$-ray diffractometry analysis of grafted and native mastic gum and acrylamide samples was done in powder form by means of X-ray diffractometer (Ultima-4, Rigaku Company, Japan) using K-beta filter, $\mathrm{CuK} \alpha$-radiation, the voltage of $40 \mathrm{kV}$ and a current of $30 \mathrm{~mA}$ The scanning employed was over the 0.00 to $60.00^{\circ}$ diffraction angles $(2 \theta)$ range [18].

\section{Scanning electron microscopy}

Scanning electron micrographs of mastic Gum and grafted gum samples were taken by using a SEM (JEOL, JSM-6100) [19].

\section{RESULTS AND DISCUSSION}

Formulation and optimization of mastic-g-poly (acrylamide)

The dried mastic gum was used for the purpose of grafting of gum by following steps as shown in fig. 1.

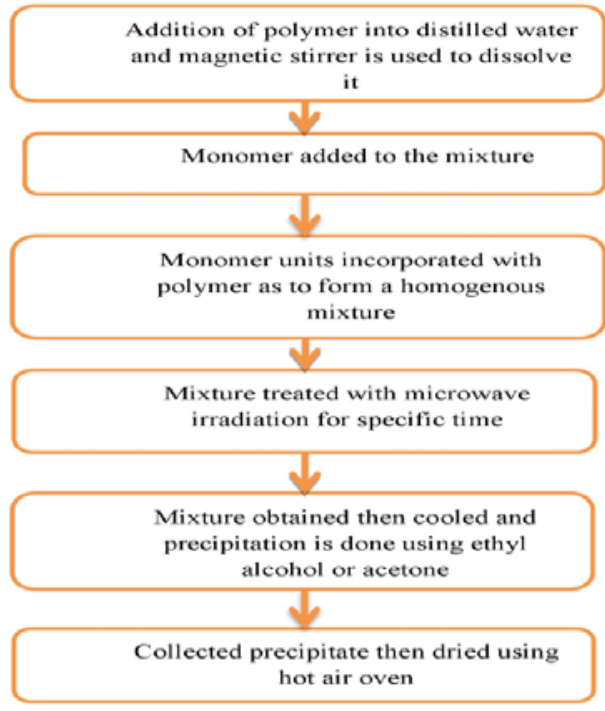

Fig. 1: Process for microwave-based grafting

In the present study, the optimization of microwave-assisted graft copolymerization of acrylamide on mastic gum has been explored by using 3-factor 3-level response surface Box-Behnken design. Levels of Independent Variables in Box Behnken Design are shown in table 1. The experimental design and result of experimental data are given in table 2.

Table 2: Box behnken design matrix

\begin{tabular}{|c|c|c|c|c|c|c|}
\hline $\begin{array}{l}\text { Formulation } \\
\text { code }\end{array}$ & $\begin{array}{l}\text { Acrylamide amount } \\
\text { (gm) }\end{array}$ & $\begin{array}{l}\text { Initiator amount } \\
\text { (mg) }\end{array}$ & $\begin{array}{l}\text { Temperature ( } \\
\left.{ }^{\circ} \mathrm{C}\right)\end{array}$ & \% Yield & $\%$ Grafting & $\begin{array}{l}\text { \% Grafting } \\
\text { efficiency }\end{array}$ \\
\hline F1 & 2.1 & 50 & 50 & 50.56604 & 168 & 32.30769 \\
\hline $\mathrm{F} 2$ & 1.4 & 75 & 50 & 57.01266 & 125.2 & 32.9474 \\
\hline F3 & 2.1 & 50 & 50 & 52.07547 & 176 & 33.84615 \\
\hline $\mathrm{F} 4$ & 1.4 & 50 & 40 & 60.51282 & 136 & 35.78947 \\
\hline F5 & 1.4 & 25 & 50 & 55.16883 & 112.4 & 28.5789 \\
\hline F6 & 2.8 & 75 & 50 & 50.66667 & 242 & 34.6667 \\
\hline F7 & 2.8 & 50 & 60 & 48.47761 & 224.8 & 34.06061 \\
\hline F8 & 2.1 & 75 & 40 & 28.03738 & 50 & 9.6154 \\
\hline F9 & 2.1 & 25 & 60 & 24 & 26 & 5 \\
\hline F10 & 2.1 & 50 & 50 & 55.24528 & 192.8 & 37.07692 \\
\hline F11 & 2.1 & 25 & 40 & 22.09524 & 16 & 3.07692 \\
\hline F12 & 2.8 & 50 & 40 & 48.62687 & 225.8 & 34.21212 \\
\hline F13 & 2.1 & 75 & 60 & 41.71963 & 123.2 & 23.69231 \\
\hline F14 & 1.4 & 50 & 60 & 75.89744 & 210 & 51.5789 \\
\hline F15 & 2.8 & 25 & 50 & 28.66165 & 90.6 & 13.7273 \\
\hline
\end{tabular}

The model proposed the following equations for \% Yield response, $\%$ Grafting response and \% Grafting Efficiency response respectively

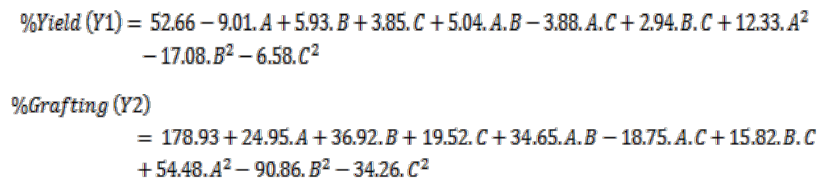

\%Grafting Efficiency (Y3)

$$
=34.41-4.02 . A+6.31 . B+3.95 . C+4.14 . A . B-3.98 . A . C+3.03 . B . C
$$$$
+10.81 \cdot A^{2}-17.74 . B^{2}-6.31 . C^{2}
$$

Where A is the amount of acrylamide, B is the amount of initiator and $\mathrm{C}$ is temperature.

The above polynomial equations explain the positive or negative effects of various independent variables on \% yield, \% grafting and 
$\%$ grafting efficiency. The amount of acrylamide showed a positive effect on \% grafting while the negative effect on \%yield and \% grafting efficiency. The amount of initiator (ceric ammonium nitrate) showed a positive effect on all three parameters. The temperature has also positive effect on all three parameters. The interaction effect A. B and B. C was found to be synergistic, while the effect $A$. $C$ was found to be negative. Similarly, the effect $A^{2}$ was found to be more significant than $B^{2}$ and $C^{2}$. In the above polynomial equations, the magnitude of coefficients revealed that the concentration of initiator (B) had maximum effect on all the three parameters $[13,14]$.

The response surface plots show the effect of different independent variables on percentage yield, percentage grafting and percentage grafting efficiency (fig. 2 to fig. 10). It was observed that the concentration of acrylamide has no significant effect on percentage yield, percentage grafting and percentage grafting efficiency however, temperature and initiator concentration have a significant effect up to a level.

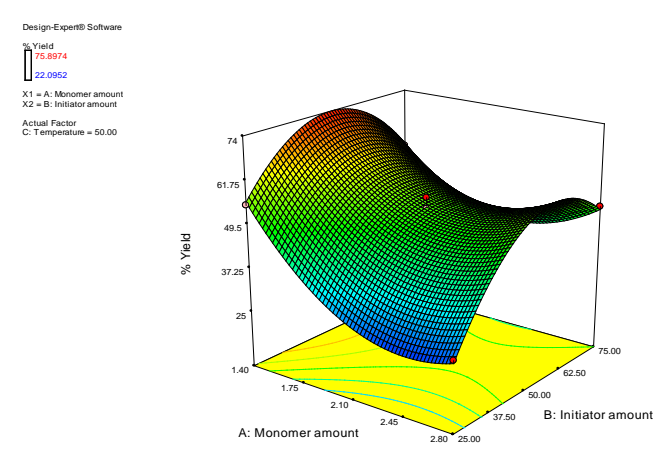

Fig. 2: 3D Surface response graph between acrylamide amount (A) and CAN amount (B) with \% yield ( $\left.\mathrm{Y}_{1}\right)$
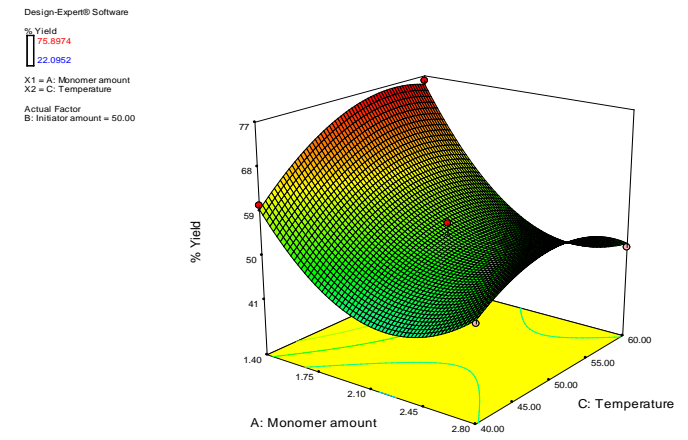

Fig. 3: 3D surface response graph between acrylamide amount (A) and temperature (C) with \% yield $\left(\mathrm{Y}_{1}\right)$

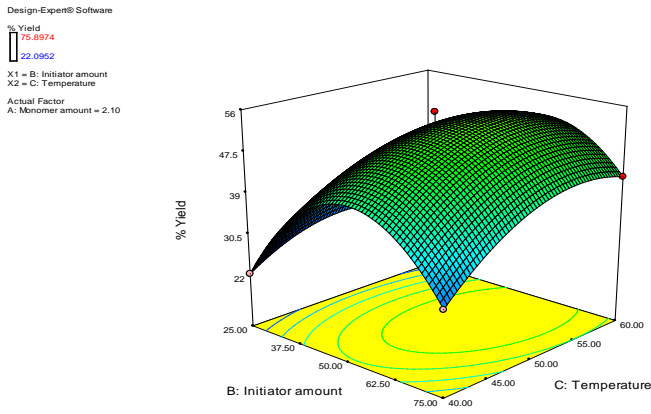

Fig. 4: 3D surface response graph between initiator amount (B) and temperature $(\mathrm{C})$ with \% yield $\left(\mathrm{Y}_{1}\right)$

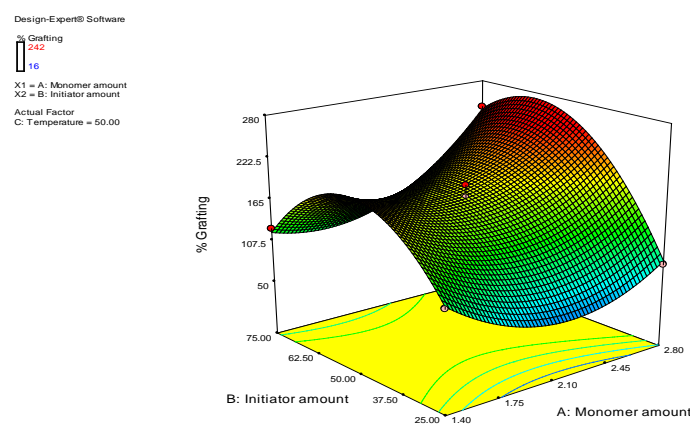

Fig. 5: 3D surface response graph between acrylamide amount (A) and CAN amount (B) with \% grafting ( $\left.\mathrm{Y}_{2}\right)$
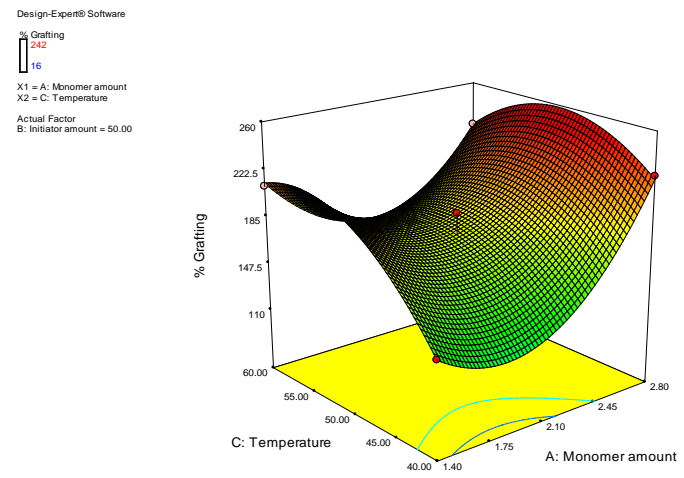

Fig. 6: 3D surface response graph between acrylamide amount (A) and temperature (C) with \% grafting ( $\left.\mathrm{Y}_{2}\right)$
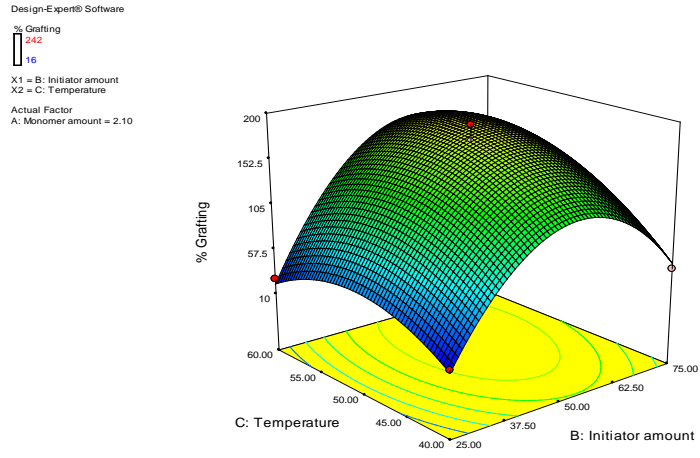

Fig. 7: 3D Surface response graph between CAN amount (B) and temperature (C) with \% grafting $\left(\mathrm{Y}_{2}\right)$
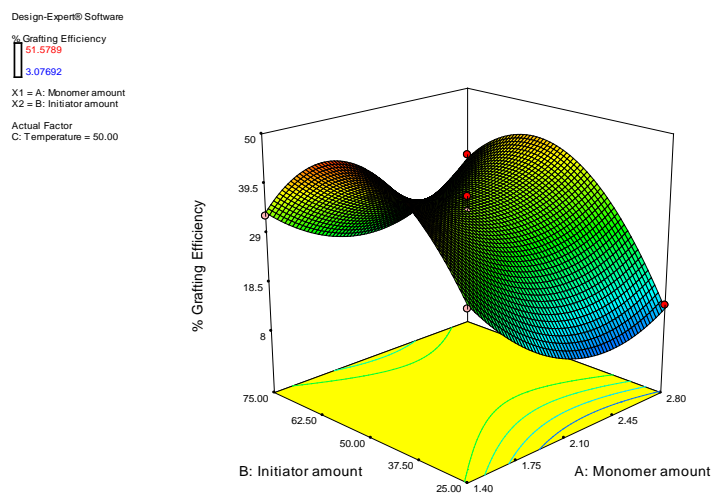

Fig. 8: 3D surface response graph between acrylamide amount (A) and CAN amount (B) with \% grafting efficiency $\left(\mathrm{Y}_{3}\right)$ 

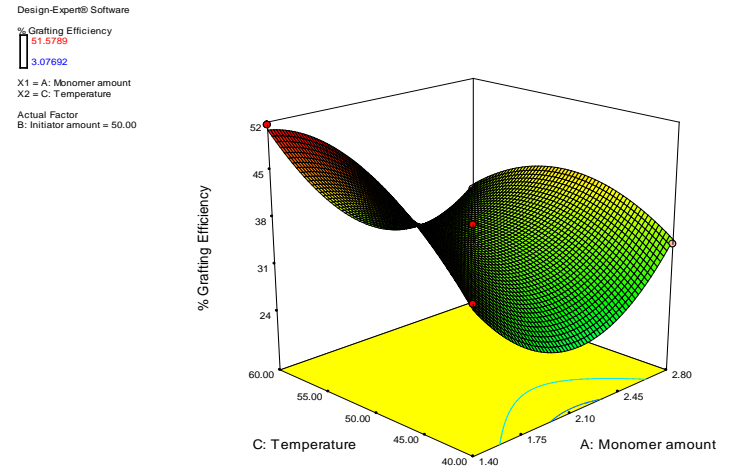

Fig. 9: 3D surface response graph between acrylamide amount (A) and temperature (C) with \% grafting efficiency $\left(\mathrm{Y}_{3}\right)$

\section{Formulation characterization}

Optimized Batch (F14) of Acrylamide grafted mastic gum obtained from numerical optimization tool was subjected to FTIR, DSC, XRD and SEM studies.

The FTIR spectra (fig. 11) of mastic gum showed the characteristic peak of Mastic Gum. The spectrum showed a C-H stretch at $2926 \mathrm{~cm}^{-}$ 1, $\mathrm{C}=0$ stretch at $1209 \mathrm{~cm}^{-1}$, =C-H bend at $929 \mathrm{~cm}^{-1}$. The FTIR spectrum of acrylamide is shown in fig. 12. The spectra of acrylamide presented absorption bands at $3340 \mathrm{~cm}^{-1}$ and $3200 \mathrm{~cm}^{-1}$ due to asymmetric and symmetric $\mathrm{NH}$ stretching of the $\mathrm{NH}$ group. $\mathrm{CO}$ stretching appeared at $1647 \mathrm{~cm}^{-1}$. The spectra also showed a band at $1300 \mathrm{~cm}^{-1}$ which can be attributed to $\mathrm{CN}$ stretching, while the $\mathrm{CH}$ stretching appeared at $1600 \mathrm{~cm}^{-1}$. The FTIR spectrum of Mastic-g- poly(acrylamide is shown in fig. 13. The FTIR spectra of grafted gum showed a broad absorption band at $2926 \mathrm{~cm}^{-1}$ due to overlap of the $\mathrm{OH}$ stretching band of mastic gum and $\mathrm{NH}$ stretching $3391 \mathrm{~cm}^{-1}$ band of acrylamide. Literature supports the above FTIR studies [20,21].

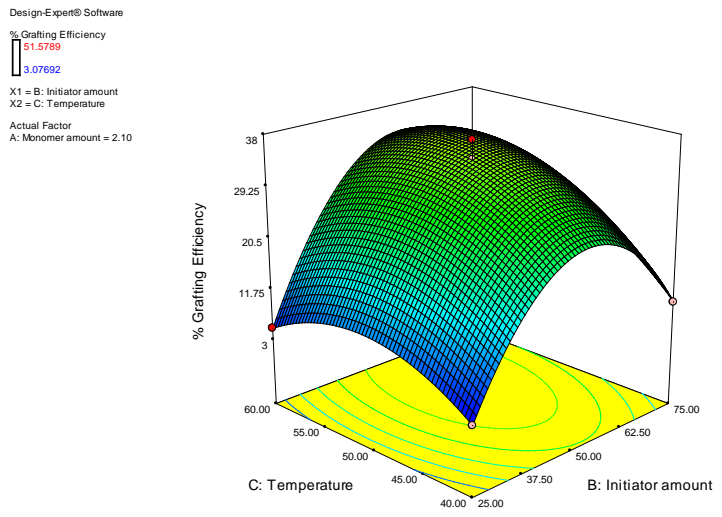

Fig. 10: 3D surface response graph between CAN amount (B) and temperature $(\mathrm{C})$ with \% grafting efficiency $\left(\mathrm{Y}_{3}\right)$

\section{Selection of optimized batch}

The optimized batch of formulation was selected by using desirability, which was calculated by using box behnken design in design expert software. F14 was selected as an optimized formulation with \% yield of 75.89744 , \% grafting of 210 and \% grafting efficiency of 51.5789 .

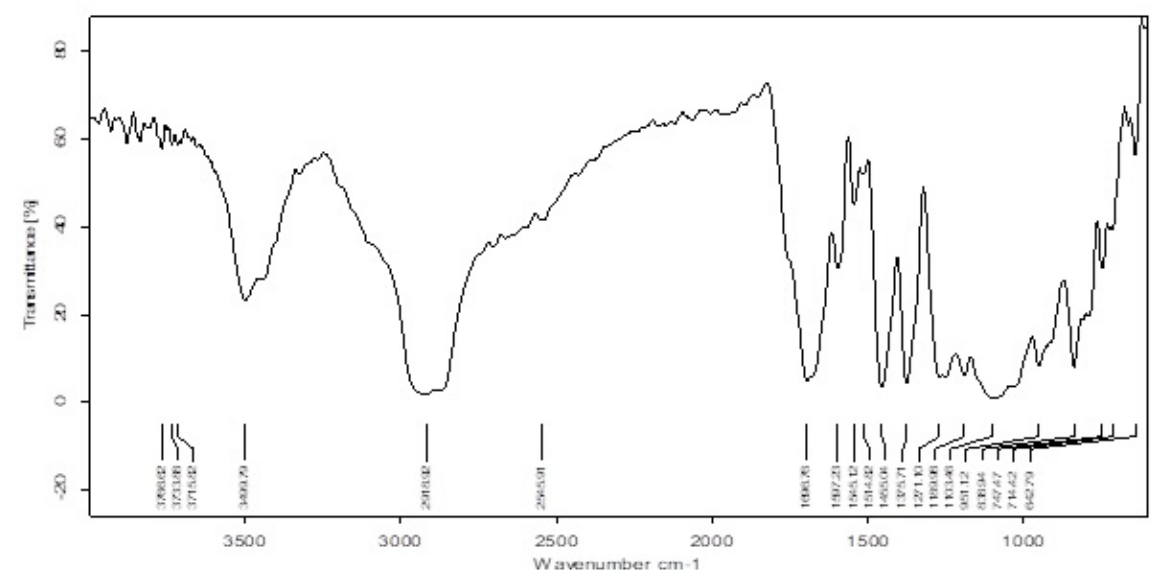

Fig. 11: FT-IR spectrum of gum mastic, acrylamide and grafted mastic gum

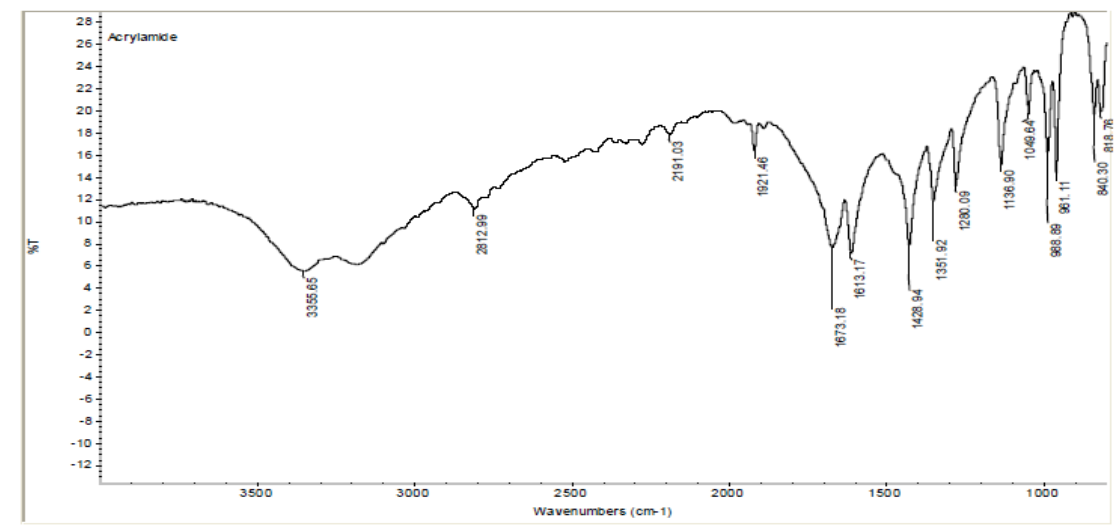

Fig. 12: FT-IR spectrum of acrylamide 


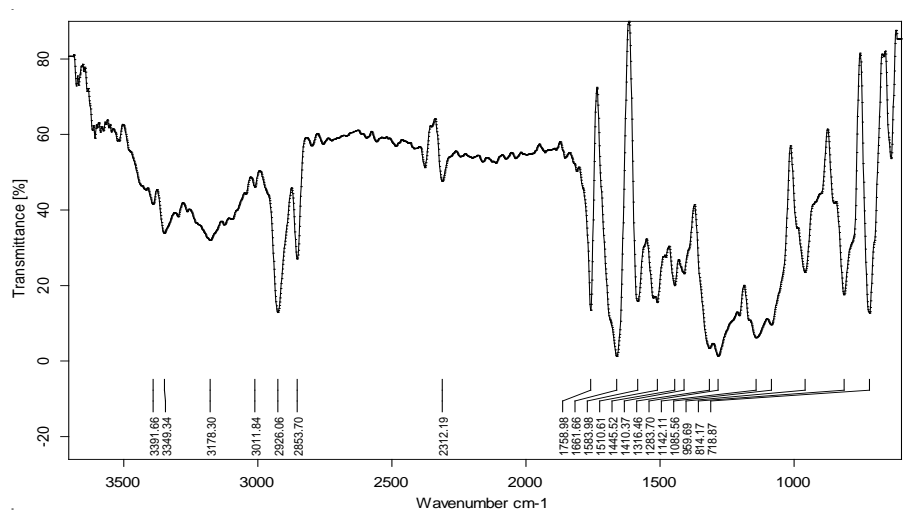

Fig. 13: FT-IR spectrum of grafted mastic gum

The fig. 14, fig. 15 and fig. 16 contains the DSC thermogram of Gum mastic, acrylamide and grafted mastic gum. An exothermic peak was observed at $254.01{ }^{\circ} \mathrm{C}$ of the grafted mastic gum. The increase in the glass transition of grafted gum is to be expected because the amine group in polyacrylamide chains grafted onto gum has more difficulty to interact. The GM-g-Polyacrylamide is expected to have longer acryl chains than Gum and acrylamide, thus more glass transition temperature [22, 23].

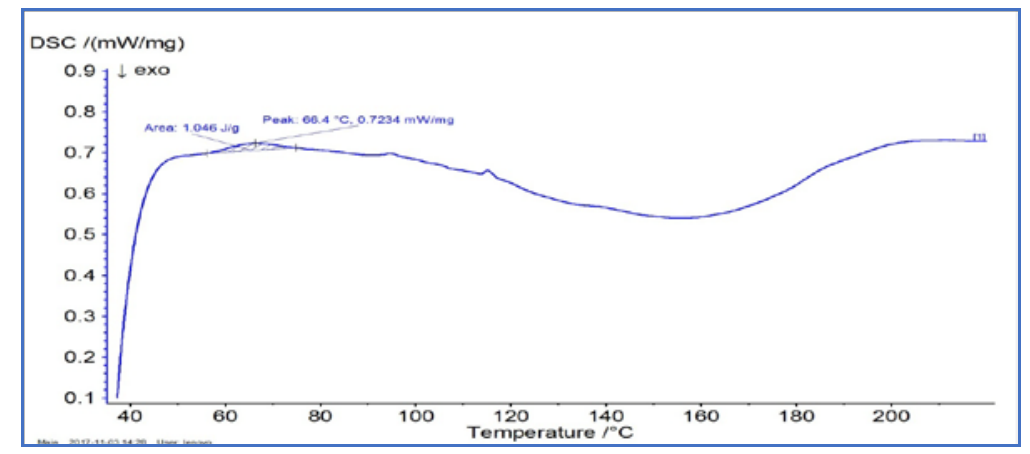

Fig. 14: DSC of mastic gum

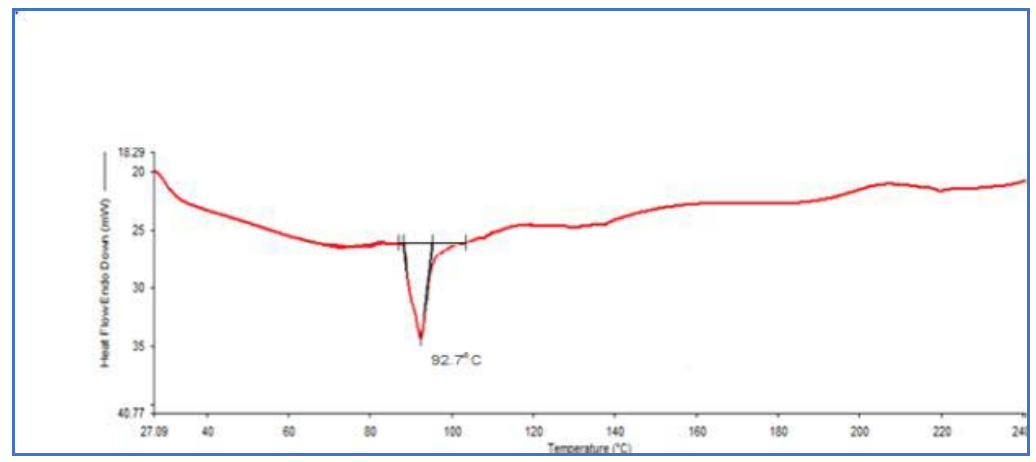

Fig. 15: DSC of acrylamide

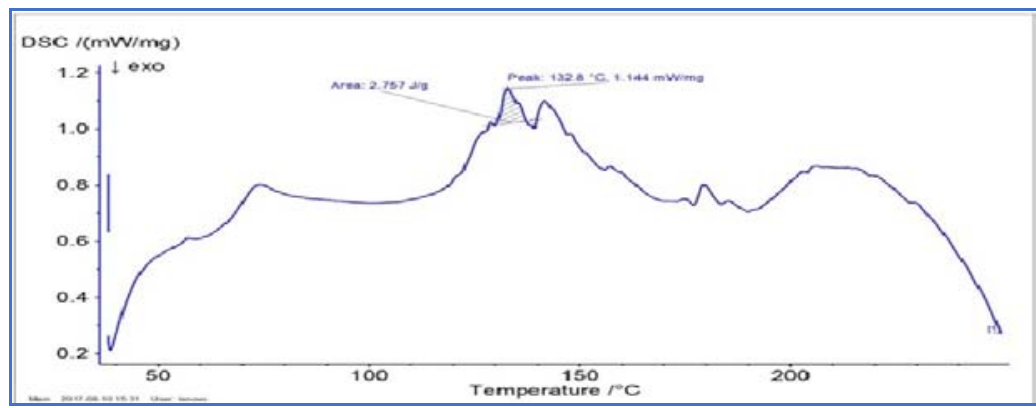

Fig. 16: DSC of grafted mastic gum 
The XRD spectra (fig. 17) showed the amorphous nature of mastic gum as no characteristic peaks in the spectrum were observed while the diffractogram of acrylamide (fig. 18) showed the crystalline nature. The XRD spectrum of grafted gum (fig. 19) showed the characteristic peaks of acrylamide but with the decreased intensity, which confirmed the formation of graft co-polymer [24, 25].

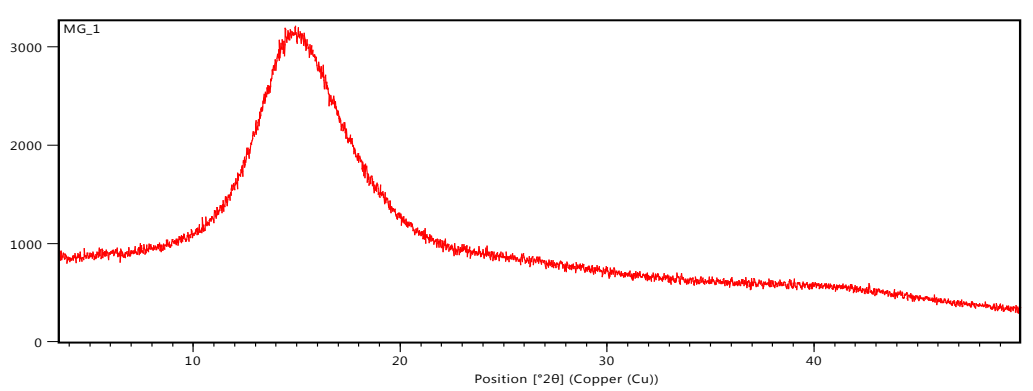

Fig. 17: XRD spectra of mastic gum

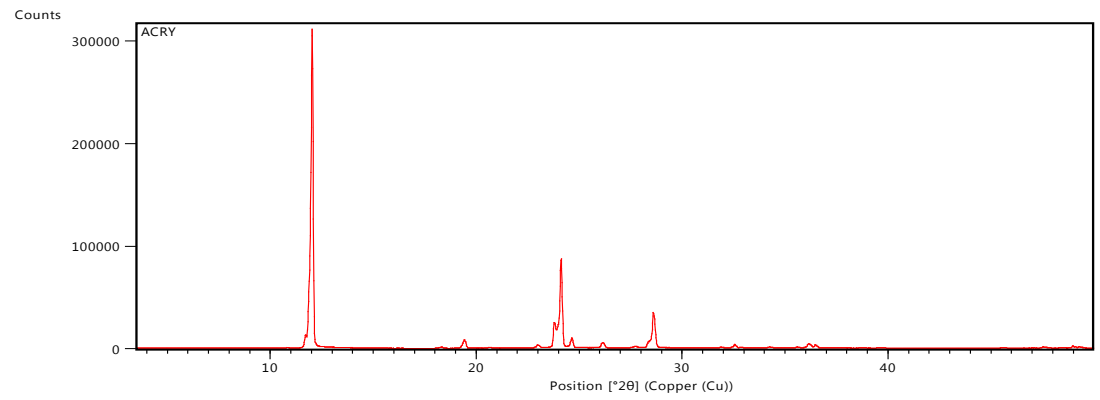

Fig. 18: XRD spectra of acrylamide

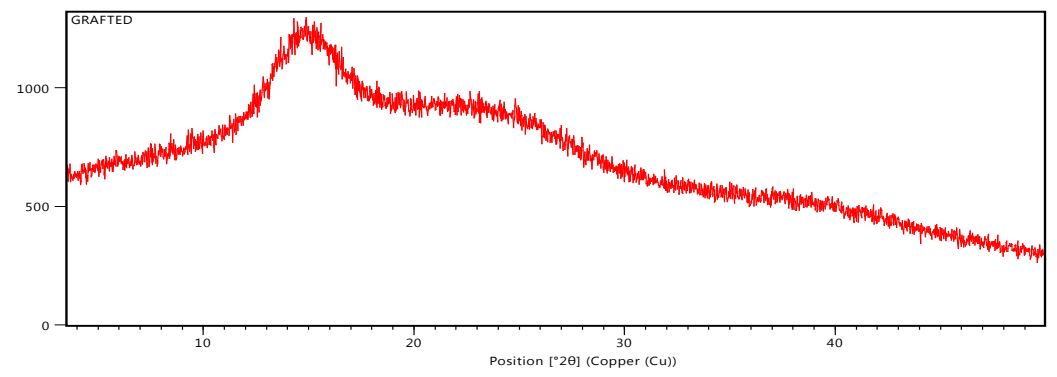

Fig. 19: XRD spectra of grafted mastic gum

The SEM studies of Mastic Gum (fig. 20) and Mastic-g-Poly (Acrylamide) (fig. 21) showed a change in surface morphology after grafting. The more roughness and unevenness on the surface of grafted gum due to the deposition of acrylamide was clearly visible [26, 27].

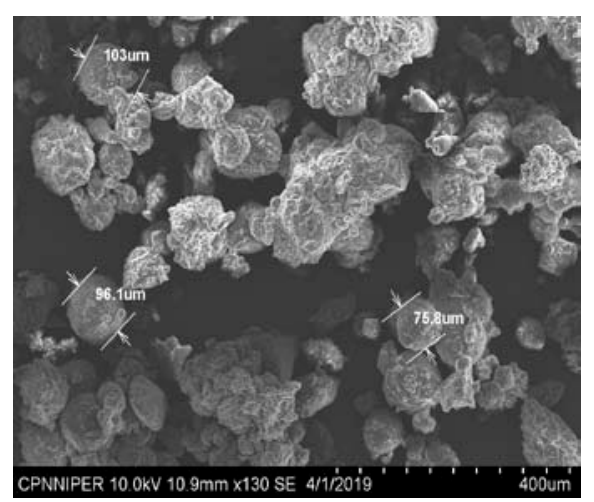

Fig. 20: Scanning electron microscopy ofmastic gum

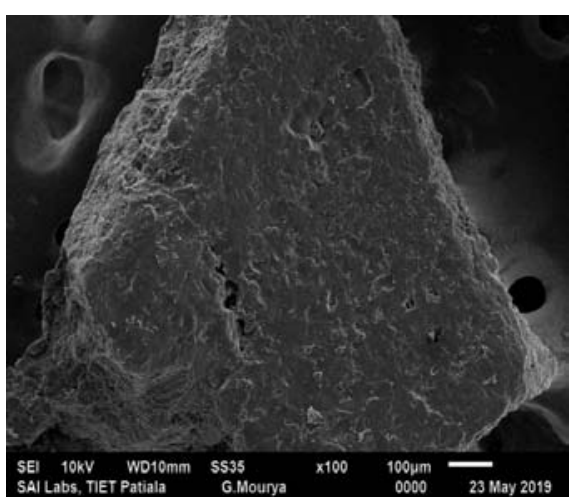

Fig. 21: Scanning electron microscopy of grafted mastic gum

\section{CONCLUSION}

Polymeric materials, because of its structure and composition, are generally used for making modified release formulations. A grafted 
co-polymer shows macromolecular series with single or multiple types of block molecule series associated with core polymeric backbone chain as various side chains. Graft polymerization is a convenient way to use natural polysaccharides like gum mastic for making modified release formulation. Nowadays in polymer science the synthesis and use of these grafted copolymers in various applications is a major area for researchers. In summary, we prepared grafted co-polymer by redox initiator method, which can be used further for the sustained release formulation.

\section{ACKNOWLEDGEMENT}

The authors are grateful to Lovely Professional University, Phagwara for providing the necessary platform for carrying out this research project.

\section{FUNDING}

Nil

\section{AUTHORS CONTRIBUTIONS}

Authors declare that the work done by the names mentioned in the article and all the liabilities and claims related to the content of the article will be borne by the authors.

\section{CONFLICT OF INTERESTS}

The authors report no conflict of interest. The authors alone are responsible for the content and writing of this article.

\section{REFERENCES}

1. Singh AV, Nath LK. Evaluation of acetylated moth bean starch as a carrier for controlled drug delivery. Int J Biol Macromol 2012;50:362-8.

2. Matyjaszewski K. Atom transfer radical polymerization: from mechanisms to applications. Isr J Chem 2012;15213:206-20.

3. Bhosale RR, Gangadharappa HV, Moin A, Gowda DV, Osmani RAM. Grafting technique with special emphasis on natural gums: applications and perspectives in drug delivery. Nat Prod J 2015;5:124-39.

4. Szwarc M. Living Polymers. Their discovery, characterization, and properties. J Polym Sci 1998;36:9-15.

5. Setia A, Kumar R. Microwave-assisted synthesis and optimization of Aegle marmelose-g-poly(acrylamide): release kinetic studies. Int J Biol Macromol 2014;65:462-70.

6. Soppimath KS, Aminabhavi TM, Dave AM, Kumbar SG, Rudzinski WE. Stimulus-Responsive" Smart" hydrogels as novel drug delivery systems. Drug Dev Ind Pharm 2002; 28:957-74.

7. Chen T, Kumar G, Harris MT, Smith PJ, Payne GF. Enzymatic grafting of hexyloxyphenol onto chitosan to alter surface and rheological properties. Biotechnol Bioeng 2000;70:564-73.

8. Wenzel A, Yanagishita H, Kitamoto D, Endo A, Haraya K, Nakane T. Effects of preparation condition of photoinduced graft fillingpolymerized membranes on pervaporation performance. J Membr Sci 2000;179:69-77.

9. Yamaki T, Asano M, Maekawa Y, Morita Y, Kubota H, Yoshida M. Radiation grafting of styrene into crosslinked PTEE films and subsequent sulfonation for fuel cell applications. J Macromol Sci Part A: Pure Appl Chem 2003;67:403-7.

10. Russell KE. Free radical graft polymerization and copolymerization at higher temperatures. Prog Polym Sci 2002;27:1007-38.
11. Kaur L, Gupta GD. Gum karaya-g-poly(acrylamide): microwaveassisted synthesis, optimization and characterisation. Int J Appl Pharm 2020;12:143-52.

12. Prashanth KVH, Tharanathan RN. Studies on graft copolymerization of chitosan with synthetic monomers. Carbohydr Polym 2003;54:343-51.

13. Abbas G, Hanif M, Khan MA. pH-responsive alginate polymeric rafts for controlled drug release by using box behnken response surface design. Des Monomers Polym 2017;20:1-9.

14. Sharma GN, Kumar CHP, Shrivastava B, Kumar B. Optimization and characterization of chitosan-based nanoparticles containing methylprednisolone using box behnken design for the treatment of crohn's disease. Int J Appl Pharm 2020;12:12-23.

15. Xie $\mathrm{W}, \mathrm{Xu} \mathrm{P}$, Wang $\mathrm{W}$, Liu Q. Preparation and antibacterial activity of a water-soluble chitosan derivative. Carbohydr Polym 2002;50:35-40.

16. Singh V, Kumar P, Sanghi R. Use of microwave irradiation in the grafting modification of the polysaccharides-a review. Prog Polym Sci 2012;37:340-64.

17. Malviya R, Kumar P, Kumar S. Modification of polysaccharides: pharmaceutical and tissue engineering applications with commercial utility (patents). Mater Sci Eng C Mater Biol Appl 2016;68:929-38

18. Kaity S, Isaac J, Kumar PM, Bose A, Wui T, Ghosh A. Microwaveassisted synthesis of acrylamide grafted locust bean gum and its application in drug delivery. Carbohydr Polym 2013; 98:1083-94.

19. Vijan V, Kaity S, Biswas S, Isaac J, Ghosh A. Microwave-assisted synthesis and characterization of acrylamide grafted gellan, application in drug delivery. Carbohydr Polym 2012;90:496506.

20. Bruni S, Guglielmi V. Molecular and biomolecular spectroscopy identification of archaeological triterpenic resins by the nonseparative techniques FTIR and 13 C NMR: the case of pistacia resin (mastic) in comparison with frankincense. Spectrochim Acta Part A 2014;121:613-22.

21. Pawar YA, Patil SH, Jadhav KR, Baviskar SR. Formulation and evaluation of matrix tablet of venlafaxine hcl by using directly compressible co-processed excipient. Int J Pharm Pharm Sci 2014;6:504-11.

22. Kaity S, Ghosh A. Facile preparation of acrylamide grafted locust bean gum-poly(vinyl alcohol) interpenetrating polymer network microspheres for controlled oral drug delivery. J Drug Delivery Sci Technol 2016;33:1-2.

23. Salih OS, Nief RA. Effect of natural and synthetic polymers on the properties of candesartan cilexetil matrix tablet prepared by dry granulation. Asian J Pharm Clin Res 2016;9:161-70.

24. Vengala P, Vanamala R. Nanocrystal technology as a tool for improving dissolution of poorly soluble drug, lornoxicam. Int J Appl Pharm 2018;10:162-8.

25. Kumari A, Jegadeeshwari LA, Gandhi NN. Optimization of green synthesized silver nanoparticles from caralluma umbellata. Int J Appl Pharm 2018;10:103-10.

26. Rao MRP, Gaikwad SR, Shevate PM. Synthesis and characterization of a novel mucoadhesive derivative of psyllium seed polysaccharide. Int J Pharm Pharm Sci 2017;9:166-75

27. Tiwari A, Singh V. Microwave-induced synthesis of electrical conducting gum acacia-graft-polyaniline. Carbohydr Polym 2008;74:427-34. 